\title{
Phenomenographic study of students' problem solving approaches in physics
}

\author{
Laura N. Walsh, Robert G. Howard, and Brian Bowe \\ Physics Education Research Group, School of Physics, Dublin Institute of Technology, Kevin Street, Dublin 8, Ireland
}

(Received 28 February 2007; published 12 December 2007)

\begin{abstract}
This paper describes ongoing research investigating student approaches to quantitative and qualitative problem solving in physics. This empirical study was conducted using a phenomenographic approach to analyze data from individual semistructured problem solving interviews with 22 introductory college physics students. The main result of the study is a hierarchical set of categories that describe the students' problem solving approaches in the context of introductory physics.
\end{abstract}

DOI: 10.1103/PhysRevSTPER.3.020108

PACS number(s): 01.40.Fk

\section{INTRODUCTION}

This study presents a set of categories that describe the problem solving state of a set of novice college physics students. This work is new within the context of the Irish and European education systems; however, parallels will be drawn with the United States education system and research carried out there. With these new categories of students' initial approaches to problem solving, teaching and assessment practices may be developed to help students advance to higher hierarchical categories of problem solving. This study was carried out in the context of an Irish school of physics, which has set up a Physics Education Research Group in order to carry out research to inform curriculum development, and teaching and assessment practices. Over the past six years the school has introduced new pedagogical approaches including problem-based learning, ${ }^{1,2}$ project-based learning, ${ }^{3}$ and peer instruction ${ }^{4}$ and this research will be used to inform these teaching practices, in particular the facilitation of group learning activities.

The research presented here is one part of a larger project that aims to explore the relationship between conceptual knowledge and problem-solving ability. This paper, however, sets out to specifically answer the following research question: How do introductory physics students approach problem solving?

While a large number of physics education research groups have carried out studies on conceptual difficulties experienced by students, fewer studies have focused on how to develop students' ability to solve quantitative problems. ${ }^{5}$ This is surprising, as one of the principal goals of a physics course is to produce adept problem solvers who can transfer their knowledge and understanding to real world situations. An issue which has been raised by a number of physics education researchers recently is whether the community is placing too much emphasis on gains in conceptual understanding, while "sacrificing problem solving skill development."6 Having said that fewer studies have investigated interventions to improve problem solving in physics, there is still extensive literature on the subject of the problem solving abilities of students. ${ }^{7-12}$ Many studies have shown that, although students can learn to solve quantitative problems by plugging values into algorithmic equations, they may not be developing the skills necessary to transfer their understanding and solve more complex problems. ${ }^{4,13-16} \mathrm{~A}$ common view throughout most of this literature is that instruction should encourage students to "think like a physicist" or result in a shift from "a novice problem solver" to "an expert problem solver." Reif and Heller ${ }^{17}$ discussed this view of student problem solvers by comparing and contrasting the problem solving abilities of novices and experts. Their findings showed that the principal difference between the two was in how they organize and use their knowledge in the context of solving a problem. Experts rapidly redescribe the problem and often use qualitative arguments to plan solutions before elaborating on them in greater mathematical detail. Novices rush into the solution by stringing together miscellaneous mathematical equations and very quickly encounter difficulties. Physicists organize their knowledge in a very structured way and therefore can call on this knowledge when and in the order that it is needed. However, novice physics students do not necessarily have this knowledge structure, as "their understanding consists of random facts and equations that have little conceptual meaning."18 This gap between expert and novice problem solvers has been well studied with an emphasis on classifying the differences between students and experts in an effort to discover how students can become more expertlike in their approach to problem solving. ${ }^{19-22}$ However, introductory physics students will rarely achieve this higher-level problem solving expertise during their first year in college, nor are they necessarily expected to. What is expected is that they begin to learn to develop a coherent knowledge structure, which they can then learn to access and "activate" appropriately in order to solve problems. ${ }^{23,24}$ One research group, among others, that has devoted a good deal of time to investigating students' different problem solving approaches is the University of Maryland Physics Education Research Group..$^{25}$ The majority of their foci have been on exploring the manner in which students activate (or don't, as the case may be) their knowledge of mathematics in order to approach physics problems. ${ }^{26-29}$ Tuminaro $^{30}$ describes students' use of mathematics in their approaches to problem solving in terms of the epistemic games ${ }^{31}$ that they play while attempting to solve the problems. This work involved the categorization of students' problem solving approaches while they worked in groups using an observational methodology. The researchers identified six epistemic games that these students played as they used mathematics to approach problem solving; these are mapping meaning to mathematics, mapping mathematics to meaning, physical mechanism games, pictorial analysis, recursive plug-and-chug, and trans- 
literation to mathematics. These epistemic games will be compared later in the paper to the categories discovered through the research presented here.

\section{RESEARCH APPROACH}

Phenomenography was chosen as the strategy of inquiry or methodology with which to answer the research question involved in this study. ${ }^{32-36}$ Phenomenography has become an established methodology in education research, as it aims to understand the various ways in which different people experience, perceive, or understand the same phenomenon. ${ }^{37-39}$ Its foundations are in educational research, where it evolved out of the desire to understand why some students are better learners than others. Although the relationship between phenomenology $\mathrm{y}^{40}$ and phenomenography has been regarded as unclear, ${ }^{41}$ and phenomenography is sometimes seen as a subset of phenomenology, it did not emerge or derive from phenomenology. ${ }^{42}$ To take a phenomenological approach is to step back from ordinary assumptions regarding things and to describe the phenomena of experience as they appear, rather than attempt to explain why they appear that way, whereas phenomenography aims to find out the qualitatively different ways of experiencing or thinking about some phenomena. ${ }^{34}$ Different people will not experience a given phenomenon in the same way, but a phenomenographic approach assumes that there are a limited number of qualitatively different ways in which different people can experience the same phenomenon.

The researcher seeks to identify the multiple conceptions, or meanings, that a particular group of people has for a particular phenomenon or a number of phenomena. Thus, the objects of study in phenomenographic research are the qualitatively different ways in which people experience or make sense of different phenomena in the world around them. The outcome of phenomenographic research is therefore a set of categories that describe the qualitative variation in the ways the sample participants (e.g., students) experience, interpret, understand, perceive, or conceptualize an object of study, a phenomenon, a concept, or an activity ${ }^{33}$ (e.g., solving physics problems). This ordered and related set of categories of descriptions is called the "outcome space" of the concept being studied. However, phenomenography is more than just identifying these conceptions and outcome spaces; it also involves looking at their underlying meanings, the relationship between them, and their implications in a given context.

In this theoretical approach, it is irrelevant if these conceptions are considered "correct" or "incorrect" by current standards. The aim is simply to elucidate the different possible conceptions that people have for a given phenomenon; moreover, it is the relation between the phenomenon and the people experiencing it that is important. The analysis involves identifying the conceptions and looking for their underlying meanings and the relationship between them. ${ }^{37} \mathrm{Al}$ though it is appropriate to answer the research question of this study using a phenomenographic approach, it is not a "pure" phenomenographic approach. Marton (Ref. 33, p. 38) suggests that the concepts under study are mostly "phenomena confronted by subjects in everyday life rather than in course material studied in school." Pure phenomenography is not appropriate, as the aim of this research is to provide information on student approaches to problem solving in order to use the outcomes in the context of learning and teaching. Therefore, a variation of phenomenography is used called "developmental phenomenography." 43 Bowden and co-workers have carried out a number of investigations into student learning in physics using a developmental phenomenographic approach. ${ }^{44,45}$ For instance, Bowden et al. ${ }^{46}$ used this research methodology to investigate students' understanding of displacement, velocity, and frames of reference. The researchers interviewed a number of first-year students about their understanding of these particular concepts, encouraging students to give full explanations of their understanding. The interviews were then transcribed and subjected to phenomenographic analysis, involving numerous members of the research group. Categories that described the variations in conceptions were drawn from the data, with the focus on the students' meaning rather than on particular sentences. These initial hierarchical categories were then reexamined and compared, until a final set of categories was constituted that represented all the variation in the data. Sharma et $a l .{ }^{47}$ also adopted a phenomenographic methodology to describe the variations in the way in which students understood the concept of gravity. Therefore, this methodology, and the methods used and developed by these researchers, were adopted to undertake the research presented here.

\section{INDIVIDUAL INTERVIEWS}

For this study, semistructured interviews were used, in which specific questions were prepared but any unexpected lines of reasoning were also followed. Although one of the aims of the interviews was to investigate student's conceptual understanding of a small number of concepts, those results are not presented here. The principal aim of the individual interviews was to examine the various ways in which the students approach quantitative physics problems.

The interviews, which were videotaped, consisted of a sequence of six physics problems with the first two being typical end-of-chapter linear motion problems. Two of the problems were adapted from context-rich questions developed by the physics education research group at the University of Minnesota. ${ }^{48}$ The problems used are presented in the Appendix. Generally the problems became progressively more complex, and therefore if a student did not complete all of the problems this was indicative of his/her problem solving ability. The interview did not have a time limit, but ended when the student could not continue. Some of the students completed all six problems, while others may have completed only two or three. Retrospectively, the interviews lasted on average 45 minutes; however, this varied, and no particular time was allotted for the interviews. For instance, one student completed all six problems in 55 minutes, whereas for another student who could attempt only two questions the interview lasted half an hour. However, for the purpose of this study, this did not pose a difficulty as it was the description of the students' problem solving approaches that was under investigation and not the students' solutions 
to the problems. The interviewer read each question aloud to the students and the students were then given time to read the problem themselves. The reason the problem was initially read aloud by the interviewer was to overcome any discrepancies in how the students read the problems. The students were asked to state their first ideas on what the problem involved and then asked to describe, qualitatively, how they were going to go about solving the problem. After this, the students were encouraged to "think aloud" 49 as they solved the problem on paper (which was collected at the end of the interview). An equation sheet was available during the interviews, containing a list of equations the students encountered during their mechanics module. Once the students had solved, or attempted to solve, the problem they were asked how confident they were in their answer and asked to explain this level of confidence. In this way each interviewee was encouraged to qualitatively analyze his/her solution. Because of the graded nature of the problems, and with the use of the thinking-aloud protocol, the students' approaches could be identified.

\section{INTERVIEW PARTICIPANTS}

Twenty-two participants were selected from four programs in a higher education institution in Ireland; two of the programs were four-year honors degree ${ }^{50}$ physics programs delivered through problem-based learning, ${ }^{1,2}$ another was a four-year honors degree medical science program, and the last was a three-year ordinary degree ${ }^{50}$ general science program. Both of the latter were delivered in a predominantly traditional manner, although the lecturers were different. The participants were all in their first year of study, and the sample comprised 12 male and 10 female students, ranging in age from 18 to 24 . The participants in the study had completed the Irish Leaving Certificate, ${ }^{51}$ which typically consists of six subjects, each taken at either higher (honors) or ordinary (pass) level. Ten of the participants had studied physics as a subject for the Leaving Certificate, either at higher (honors) or ordinary (pass) level. This two-year course of study is a broad introduction to physics and covers the general areas of mechanics, optics, heat and temperature, sound, electricity, and modern physics. The participants for the interviews were chosen based on the results of a diagnostic tool, the Force and Motion Conceptual Evaluation (FMCE), ${ }^{52}$ in order to obtain a cohort with a cross section of abilities. The FMCE is a 47-item research-based, multiplechoice assessment that was designed to "probe conceptual understanding of Newtonian mechanics" (Ref. 52, p. 338). The students' results were grouped as low, medium, and high, and a similar number of students were randomly chosen from each group. The chosen students were contacted and asked to volunteer for the interviews; only three declined, which was encouraging as no incentive was offered. The interviews were carried out over a two-week period, following six weeks of formal instruction in mechanics. In addition to the student interviews, one instructor interview was conducted with a member of the physics faculty. The procedure for this interview followed that of the others; the instructor was asked to talk aloud during the interview, and it was videotaped. This instructor interview and its purpose will be discussed in some detail in the following sections.

\section{METHOD OF ANALYSIS}

The interviews were transcribed verbatim from the videotapes and used in conjunction with the students' written solutions to ensure all data were accounted for. In analyzing the data, qualitatively distinct categories were identified that described the students' approaches to problem solving. Transcripts of the students' interviews were examined independently by three members of the research group, looking for both similarities and differences among them, selecting significant statements, and comparing these statements in order to find cases of variation or agreement, and thus grouping them accordingly. Through this process initial categories were developed by each of the three researchers that described the students' approaches to problem solving, with the initial categories developed using only a subset of the interview transcripts. Once this initial categorization was complete, the researchers met to discuss their categories and their interpretation of the solutions. The categories were then revised until the researchers reached a consensus about the final set of categories.

An outcome space was developed that included the minimum number of categories which explained all the variations in the data. With these categories in mind all the interview transcripts were reexamined, to determine if the categories were sufficiently descriptive and indicative of the data. This iterative data analysis procedure is consistent with the phenomenographic approach, ${ }^{43}$ as Marton (Ref. 32, p. 43) states that "definition for categories are tested against the data, adjusted, retested, and adjusted again."

The instructor interview was not included in the phenomenographic analysis, as the aim of the analysis was to develop a scheme for categorizing the problem solving state of a class of students. The interview with the lecturer was conducted solely to provide data for comparative purposes.

\section{RESEARCH FINDINGS}

The analysis of the interview transcripts revealed a hierarchical set of categories that describes the interview participants' approaches to solving quantitative physics problems (Table I). The categories are all internally related and are described using two components: How do these students approach problem solving? and what is the focus of their approach? Table I outlines the categories, the key characteristics of each category, and the number of students in each category. Each category is then described in some detail, with an example of a student's problem solving sequence for one of the problems. However, it should be noted that it is the problem solving approaches that the students use on all of the problems that define the categories, not just the one example shown here; this is just for illustration purposes. Therefore, in the individual examples given below, the students may not display all the key characteristics, but they do over the course of doing all the problems. 
TABLE I. Outcome space of students' approaches to problem solving.

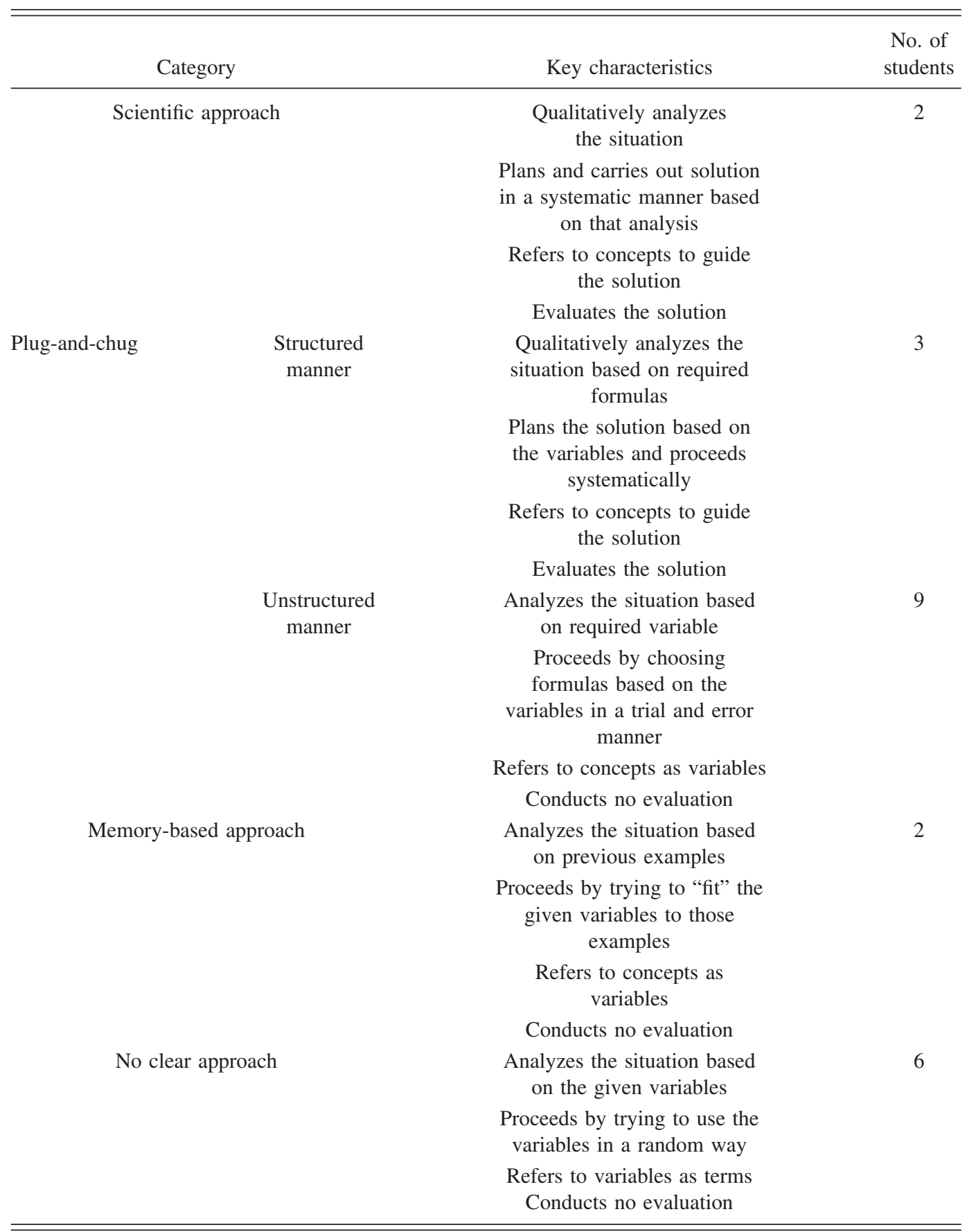

\section{Scientific approach}

Students that use this approach to solve problems qualitatively evaluate the physical situation by referring to the physics concepts involved. These students identify the concepts that would be involved in solving the problem and discuss, in a coherent manner, the way in which those concepts relate to the problem. These students outline a plan for solving the problem and then identify the variables that will be used to find an answer. Within this small group, the students are familiar with the equations that they require to solve the problem (they do not need to refer to the equation sheet). The students use the information they have to solve the problem, but they may not always get the correct answer due to either a mathematical mistake or a conceptual problem. The focus throughout the solution process is on how the concepts are related, using this to guide the solution. Interestingly, these students draw a physical representation only when they believe it will help them visualize the problem; the majority of the time they rely on their qualitative evaluation. These students evaluate their solutions either qualitatively or by defending or dismissing the numerical value they have obtained based on what they believe the solution should be. Below is an example of a student (student 3 ) using this approach to solve problem 3 . 
Student: $\quad$ OK so, I'm going at $10 \mathrm{~m} / \mathrm{s}$ and "your friend is going to pass you."

Reading the problem again

Student: $\quad$ Now I guess when it says here that they are going to pass you at what you estimate to be a constant $15 \mathrm{~m} / \mathrm{s}$, I'm going..., I could take that as she is moving at $15 \mathrm{~m} / \mathrm{s}$ or I could take it that she is going $15 \mathrm{~m} / \mathrm{s}$ faster than you. But if I just take it she is going at 15, then the speed difference is $5 \mathrm{~m} / \mathrm{s}$. Is it cool if I draw it out?

Interviewer: Sure.

Student now draws a simple sketch of the situation

Student: $\quad$ So then I start to accelerate at a constant, so my acceleration is $0.25 \mathrm{~m} / \mathrm{s}^{2}$ until I catch her, right?

Interviewer: $O K$.

Student: $\quad$ So basically I want the distances to be the same and when I pass her, I'm going to be going faster than her. So I can use simultaneous equations to work how long she will be ahead of me.

$O K$, so if she travels faster, if I pass her at some distance $d$, her velocity is constant, she is not accelerating so her distance she travels is going to be $d$ and the distance I travel will also be $d$.

Writes

$$
\begin{gathered}
d=u t+\frac{1}{2} a t^{2}, \\
d_{\mathrm{her}}=(15) t+0, \\
d_{\mathrm{me}}=(10) t+\frac{1}{2}(0.25) t^{2} .
\end{gathered}
$$

Student: $\quad$ And we can equate those two and I get...

Writes

$$
(15) t=(10) t+(0.125) t^{2} \text {. }
$$

Student: $\quad$ Cancel one of the t's, [Writes]

$$
\begin{gathered}
15=10+0.125 t, \\
5 / 0.125=t, \\
t=40 \mathrm{secs} .
\end{gathered}
$$

Student: $\quad$ So $t=40$ seconds. [Looking back over the problem and solution.] So it's just the time they're looking for, how long she was ahead of you. So I think that's right.

Interestingly, students who were categorized as having a scientific approach to problem solving could in fact apply a plug-and-chug approach when solving a lower-level problem. Generally, they would still analyze the situation to begin with, but would then simply choose an appropriate formula and solve the problem. It became apparent that the students were using a scientific approach only when they were faced with higher-level problems and a strategic approach was necessary. This is discussed in more detail in the Discussion section of the paper.
Plug-and-chug

\section{Structured manner}

Students who approach problem solving in this way evaluate the problem by stating what formulas or type of formula will be used to solve the problem. These students relate the concepts to the variables that are involved and identify the target variable. In this way they plan their solution based on the variables given in the problem and they immediately seek an appropriate formula; thus they identify the variables that are not given, but are needed for a solution to be found. These students often come across obstacles, because even though they are using a problem solving strategy, it is based primarily on the variables they are using rather than on a solid analysis of the physical situation. However, the focus throughout the solution process is on how the concepts are related, and they use this to guide the solution. These students evaluate their solutions either qualitatively or by defending or dismissing the numerical value they have obtained based on what they believe the solution should be. Below is an example of a student (student 10) using this approach to solve problem 3 .

Student: Well she passes, she is going $15 \mathrm{~m} / \mathrm{s}$ and you are going $10 \mathrm{~m} / \mathrm{s}$, so you have to, em.... Well the distance will have to be the same, the distance traveled, we're going to have $u$, $v, a, s, t$ for the two of them, where the distances are equal and initial velocity is $10 \mathrm{~m} / \mathrm{s}$, final velocity we don't know, no wait, "until you pass her" so the final velocity is the $15 \mathrm{~m} / \mathrm{s}$ because er stop accelerating once we reach her speed.

All the while is writing
$\mathrm{Me}$

$u_{1}=10 \mathrm{~m} / \mathrm{s}$

$v_{1}=$

$a_{1}=0.25 \mathrm{~m} / \mathrm{s}$

$s_{1}=$ ?

$t_{1}=$ ?
Friend

$u_{2}=15$

$v_{2}=15$

$a_{2}=0$

$s_{2}=$ ?

$t_{2}=$ ?
Student: You're acceleration is $0.25 \mathrm{~m} / \mathrm{s}$ and the time is ...The time will actually be equal, oh wait...

Student rereads the problem

Ah I'll get back to that, your friend.... So we don't know the distance and we don't know the times.

Student: $\quad$ The times are obviously... The distance will be equal, the same, so that's $s_{1}=s_{2}$. And I want one [an equation] that has, want one that has an s in it. We don't want acceleration involved.

Interviewer: You don't? For your friend?

Student: $\quad$ No cause that. [Points to $a_{2}=0$.] 
Interviewer: $O K$, so what are you trying to figure out?

Student: I'm trying to figure out the time it takes for me to reach her.

Interviewer: $O K$

Student: [Rereads problem.] OK so you're moving at $10 \mathrm{~m} / \mathrm{s}$, she's moving at 15, then she passes you, then you begin to accelerate and you want to find the time it takes to catch up to her. $v=u+a t$, you'll catch up to her in that time

Writes

$$
\begin{gathered}
v=u+a t, \\
15=10+0.25 t, \\
15-10 / 0.25=t, \\
20 \text { seconds. }
\end{gathered}
$$

Student: It's 20 seconds for you to go from 10 to 15 but...Ah wait, your final velocity isn't 15, you're trying to catch up to her, so you don't know v. I'm going at 10, she's going at 15, so let's just say, after, I'm accelerating but during the time I'm accelerating she is still going at 15, so when I reach 15, I haven't traveled the same distance she has, so I've been...at 1 second I'm traveling at 10, next second at 10.25, continues up to 15 , so the final velocity wouldn't be the same, we don't know the final velocity.

Interviewer: $O K$

Student: $\quad$ But we do know the distance that we, that's for sure. We want to find the time, for me we're going to use an equation that has $u$, $a, s, t$. I don't like using that one!

Pointing to $s=u t+\frac{1}{2} a t^{2}$. However, the student writes it out anyway.

Student: $\quad$ And for the friend we want $u, v, a, s$, and $t$. That's $v^{2}=u^{2}+2 a s$.

Writes

$$
\begin{gathered}
v^{2}=u^{2}+2 a s, \\
v_{2}^{2}-u_{2}^{2} / 2 a_{2}=s, \\
u_{1} t_{1}+\frac{1}{2} a_{1} t_{1}^{2}=v_{2}^{2}-u_{2}^{2} / 2 a_{2} .
\end{gathered}
$$

Writes

In this [above] we have everything, we have every value except $t$, so I'll just put in the values.

Writes

$$
(10) t+\frac{1}{2}(0.25)(t)^{2}=
$$

Student: I don't like with the...Oh wait, I know what we can do, make it easier, we can just bring down their speeds to make it zero relative velocity.

The student does this but fails to notice until the end of the solution that $a_{2}$ is zero; the interview lasts for some time longer but the student does not achieve a correct answer. This is characteristic of this approach in that, although the student has planned the solution correctly, he has relied on the variables and the equations involved.

\section{Unstructured manner}

Students who approach problem solving in this way evaluate the problems by concentrating solely on identifying the variable that is required. These students relate the variables that are given in the problem to formulas that they believe they can use to solve the problem. They identify the variables and equations correctly, but may not notice that the manner in which they are solving the problem is incorrect or does not in fact answer the question. This group of students has difficulty when it is necessary to manipulate a formula or combine a number of concepts to solve a problem. Students in this category may choose an appropriate formula, which could in principle produce a correct answer, but many do not actually find a correct answer. This is mainly due to the incoherency in the structure of their solutions. The focus throughout the process is on the variables; these students do not attempt to relate the concepts to the variables in order to guide the solution. These students do not make an attempt to evaluate their solution, if they obtain an answer they accept that answer as correct; "otherwise it wouldn't work out." The following is an example of a student (student 21) using this approach while attempting to solve problem 2 . In this example, the student finishes with a quadratic equation and believes that once the equation was solved the answer would be $t$. However she does not attempt to solve the equation. Problem 2 is used as an example in this case as many of the students in this category could not solve the higher-level problems (problems 3-6) and therefore this problem best serves to highlight the characteristics of the approach.

Student: $\quad$ Equations of linear motion again, looking for time.

Student immediately starts writing:

$$
\begin{gathered}
u-15, \quad v-, \\
a \cdots 9.81, \quad t-?, \\
s-2 m, \quad s=u t+\frac{1}{2} a t^{2} .
\end{gathered}
$$

Interviewer: So you're using $s=u t+\frac{1}{2} a t^{2}$ to find what?

Student To find $t$.

Interviewer $O K$.

Student Cause you have $u, s$, and $a$.

Writes

$$
\begin{gathered}
2=15(t)+\frac{1}{2}(-9.81) t^{2} \\
2=15 t-19.62 t^{2} \\
19.62 t^{2}+15 t-2=0 .
\end{gathered}
$$

Student: I don't know [inaudible] [giggles].

Interviewer: So what's happened, what's wrong?

Student: $\quad$ Working out $t$, so you bring... [pause].

Student: Bring these over is it? [Talking about $-19.62 t^{2}+15 t-2=0$.]

Interviewer: So you have a $t^{2}$ value and a $t$ value. 
Student: $\quad$ Yes

Student is quiet for a while.

Interviewer: $O K$, so?

Student: So that,...You don't just add them?

Interviewer: $\mathrm{No}$

Student: $\quad$ You have to get the t's to one side.

Interviewer: It's a quadratic equation isn't it?

Student: Yeah.

Student is still trying to figure out what to do with $t$.

Student: Then you do it out.

Interviewer: So you used s as 2, displacement?

Student: $\quad$ Yeah, oh no.

Student looks at question

Student: $\quad Y e a h$, it's the distance above the ground.

Interviewer: So the ball went up and came back down.

Motions with hand up and down

Student: $\quad$ Yeah and that was two meters.

Indicating position of hand holding the ball.

Interviewer: Well your hand is there and the ball went up and came back down and the distance between your hand and the ground is $2 \mathrm{~m}$.

Student: $\quad$ Oh, so you have to double that, no you shouldn't double it but it should be more [motions upwards with hand] because it went up, is that what you mean?

Interviewer: I'm just asking you what displacement is.

Student: $\quad$ That's not it, that shouldn't be it.

Interviewer: It shouldn't?

Student: No, but I don't know what it should be.

Interviewer: OK but you're not happy using the quadratic equation?

Student: $\quad$ No.

Interviewer: Any other ideas?

Student: $\quad$ No.

\section{Memory-based approach}

Students who approach problem solving in this way analyze the problem based on situations that they have encountered in the past. They do this either by trying to recall the type of equation that they should use or by relating the problem to a similar one, done perhaps in class. Proceeding in the same way as students from the unstructured plug-and-chug category, these students relate the variables that are given in the problem to formulas that they believe they can use to solve the problem, and the focus of the solution is not based on the concepts that are involved. However, this is based upon their assumption that the problem can be solved in the same way as the previously encountered one. This could be compared to solving by analogy; however, the focus is not on the concepts involved but simply on the variables in the problem, and therefore the solution is not based on a solid representation of the problem at hand.
Again, students in this category are sometimes successful in answering the problem, this time, by remembering a process or similar problem that they have encountered. In the following example the student (student 17) actually makes an accurate analysis of the situation in problem 3. However, she is basing the analysis on another problem, which she could not complete the first time, and as a result she does not try to understand or use this analysis to solve the problem.

Student: $\quad$ This is a rotten question.

Interviewer: So what is happening?

Student: $\quad$ So I start accelerating just as she passes me, at the same point, she's traveling at 15 without accelerating and I'm traveling at 10, starting to accelerate. How long will she be ahead of me? Oh I hate these questions.

Interviewer: So what do you think?

Student: $\quad$ I think I did this a couple of weeks ago, I just can't remember.

Interviewer: Really? And what do you associate it with?

Student: What do you mean?

Interviewer: You say, "I think we did this a couple of weeks ago." What is this?

Student: $\quad A h$, really questions to do with cars and buses going up to traffic lights and going as fast as the other, exactly like this but I never liked it.

Interviewer: OK, how would you have gone about that situation?

Student: We had a distance in it and used the equations of motion.

Interviewer: And how?

Student: $\quad$ The idea was that they both passed a point at a certain..., they both passed a point at the same time. They traveled a distance...its actually the same question.

Interviewer: Oh, really?

Student: $\quad$ Yeah and I can't remember how to do it, so it's annoying me.

Interviewer: OK, so do you have any idea how to start?

Student: $\quad$ Normally I just work around it, and I figure something out.

Interviewer: Did you do this in class or tutorial?

Student: In class, then I got the answer completely wrong, so it really doesn't help me.

The interview continues with the student restating everything in the problem; however, she cannot and does not attempt to quantitatively solve the problem.

\section{No clear approach}

Students who are positioned in this category do not try to approach the problem with any sort of strategy; they analyze the situation in terms of the variables that are given in the problem. However, these students do not refer to the vari- 
ables as concepts; rather they discuss them as unrelated terms or letters, as can be seen from the following example. Therefore the focus of this process is not on the concepts involved, nor is it based on any particular method of solution. This group of students tends to try to manipulate the given variables in a rather random way to give an answer. These students are generally not faithful to any particular line of reasoning; if the interviewer questions them on a matter they are likely to change their strategy very easily. These students make no attempt to evaluate a solution that they may obtain, and this seems to be because they have no confidence in the process or strategy that they employed. The following example shows a student (student 13) using this approach to solve problem 2 .

Student: $\quad$ Same as the last one, except it is in the opposite direction.

Student is quiet for some time

Interviewer: So what do you know?

Student: $\quad$ The height and the speed.

Interviewer: Maybe if you draw it, it will help you picture it

Interviewer would not usually suggest this but the student clearly did not know how to proceed.

Student: My drawing is not very good.

The student now draws a simple sketch of the situtation.

Interviewer: What is the acceleration of the ball?

Student: 15.

Interviewer: What force is going to be acting on the ball?

Student: When it's in your hand?

Interviewer: When it has left your hand.

Student: Ah...em...gravity.

Interviewer: $O K$, so what is the acceleration of the ball?

Student: $\quad 9.8$.

Student again is quiet for some time.

Interviewer: So what do you want to work out?

Student: $\quad$ So we're looking for $t$.

Student is constantly looking at the equation sheet.

Interviewer: You may not be able to get straight to $t$.

Student: $\quad$ Ah yeah, $O K$.

Again student is quiet and simply looking at the sheet.

Interviewer: So do you know the displacement?

Student: $\quad$ No, ah, I do

[Writes] $s=2, v=$. [Stops].

Interviewer: OK so what do you need to do now?

Student: $\quad I$ want to find $v$.

[Writes] $v=\Delta s / \Delta t$.

After this, the interviewer prompts the student and she uses the equations of motion to find an incorrect answer. As mentioned earlier, the categories were constituted from all of the data and taking each interview transcript as a whole; therefore the single examples shown here may not show all of the characteristics for all of the categories.

\section{DISCUSSION}

The categories describing the approaches to problem solving exhibited by this cohort of students are composed of similar components, and yet they represent the qualitatively different ways in which these students approach problem solving. In certain cases, two categories may have a common component, yet this serves to further define and relate the categories in terms of the variation in the approaches. An example of this can be seen between the scientific approach and the structured plug-and-chug approach: in each case, students focus on the concepts to guide their solution; however, they approach problem solving in different ways. Tuminaro ${ }^{30}$ describes the "epistemic games" that students play when solving problems, which were developed by observing "episodes" of groups of students as they solved homework problems. The emphasis of Tuminaro's categories is on the students' use of mathematics in their approaches to problem solving; however, many similarities can be drawn between those epistemic games and the outcome space of problem solving approaches presented here. The "mapping meaning to mathematics" game can be closely compared with the scientific approach constituted from these data; likewise, the mapping mathematics to meaning can be compared with the structured plug-and-chug category. The game "pictorial analysis" is not specifically related to any single one of the categories presented here; however, the "recursive plug-andchug" game is closely related to the unstructured plug-andchug category. Interestingly, the lowest hierarchical epistemic game, "transliteration to mathematics," can be compared to the memory-based approach in that the students approach the problem by trying to find a solution pattern that seems to match the current problem. Although it was not the intention of the research presented here to investigate students' use of mathematics, but rather to present a set of categories which allowed for a better description of novice problem solvers, the results produced by both sets of research serve to imply that these categories could be used to track student progress during a typical year of study of introductory physics.

The categories presented here confirm that the majority of students do not approach physics problems qualitatively. Van Heuvelen ${ }^{18}$ suggests that physicists approach a problem by qualitatively analyzing the situation and then constructing a diagrammatical or graphical representation of it. Meltzer ${ }^{12}$ agrees that qualitative representation of a situation is an important factor in problem solving, and that introductory students often find it difficult to do this. Only a small number of these students actually attempted to make a diagrammatical analysis of the problems, and an interesting result here was that the students who did draw a physical representation did not do so for all of the problems that they approached. In an effort to compare the students' approaches to that of an expert, an instructor from the same institution was asked to carry out an individual interview. One of the most obvious points of departure in this interview was the instructor's tendency to immediately and always draw a diagram of the physical situation. The instructor was asked to think aloud as he solved the problem, as were the students who had participated. Another clear difference in the instructor's approach 
was that he initially approached the problems using the concepts involved rather than stating the equations that would be employed. For example in problem 1, his "first thought" was conservation of energy rather than linear motion equations. It is also interesting to note here that none of the interview participants approached problem 1 using conservation of energy. The instructor explicitly stated any assumptions he was making in solving the problem, for instance, again in problem 1, 'I'm assuming it's being dropped from rest so you have its potential energy, $m g h$. I'm assuming that is equal to its kinetic energy just before it hits the ground." Again, none of the interview participants did this; furthermore, many of the students did not pay sufficient attention to the wording in the problems. They approached the problems impulsively, often skimming over them and deciding on an approach and then changing their minds about the process repeatedly.

Problem 1 required little problem solving ability in order to solve it, and as long as the student understood that the watermelon would accelerate due to gravity and identified the variables of displacement and velocity, they simply needed to choose an appropriate kinematics equation (which is a very simple form of problem solving). Worryingly, a number of students had to be prompted about the acceleration involved; however, this is not discussed here as it forms part of another study involving students' use of their conceptual knowledge, which will be presented in future. Many students from the plug-and-chug and memory-based categories used a trial and error approach with the equations; however, in most cases the students obtained the correct answer.

On the other hand, problem 3 required little conceptual understanding in order to solve it. In this case the students had to realize that both cyclists would travel the same distance in the same time and use simultaneous equations. Therefore this problem may not have been a typical problem that the students would encounter in class. However, when confronted with this problem most of the students did not approach the problem in a structured manner. Many simply calculated how long it would take to increase velocity until they had reached the velocity of the faster cyclist, while not taking into account that the faster cyclist is moving forward all the time. Of the few students who did recognize that the displacement of both cyclists would be the same, only a small number of students attempted to use simultaneous equations to solve the problem. This problem required a more sophisticated problem solving strategy, as it required students to see the big picture. This problem must be approached as a whole rather than attempting to solve it in parts, but most students approached it by breaking it up into the two cyclists' independent journeys. This problem posed no difficulty for the instructor, who immediately made a diagrammatic representation of the problem before he qualitatively analyzed it and stated the assumptions that he was making. He continued by determining his goal, constructing his plan, and finally executing his plan. When he had obtained a quantitative answer, he looked back over his work and the problem itself before concluding that he believed his answer was correct.

As previously mentioned, another interesting finding that emerged from analysis of the interview data was that a person categorized as taking a scientific approach to problem solving could simply use a plug-and-chug technique for certain problems when appropriate. This means that, if a problem only required a student to use a certain formula, then students who had a scientific approach could simply plug the variables into the formula and obtain a correct answer. This is consistent with how experts would approach problem solving, when they are confronted with a simple algorithmic problem. ${ }^{19}$ However, these students are confident, not only in their approach, but in their choice and use of the appropriate formulas. But students who depended predominantly on the plug-and-chug approach cannot adopt the scientific approach when the plug-and-chug approach is not adequate. The type of problem typical of end-of-chapter problems ${ }^{53}$ and some examination questions could be solved by students within the plug-and-chug structured category, as these students tend to use a somewhat strategic approach when solving the problems. However, as the problems become more complex, the strategy of simply identifying the correct variables is no longer adequate. Heller and Hollaugh ${ }^{8}$ among others ${ }^{7,22}$ have highlighted the need for students to be able to solve realworld, context-rich problems. The research presented here demonstrates that the majority of students could not solve these problems and verifies that problem solving skills should be an explicit element of instruction. Hoellwarth et $a l .{ }^{6}$ discussed the need for students to learn both concepts and problem solving skills, and this is tentatively verified within the research shown here, as those students who showed a gain in conceptual understanding, as measured by the FMCE, ${ }^{52}$ also showed higher-level problem solving skills. However, this is not within the scope of this paper, and a larger number of students and further studies are needed for this result to be statistically significant.

Those students categorized as unstructured could attempt the end-of-chapter type problems, and may obtain an answer, but may not know or recognize that the approach or answer was incorrect; and this is also true for those students categorized as memory based. However, those students who are described as having no clear approach would find it quite difficult to solve typical end-of-chapter problems, as they do not seem to use any coherent knowledge structure with which to solve the problems.

These categories describe the problem solving approaches of a set of novice problem solvers. None of these students could be categorized as experts, as much more than a strategic approach is expected from an expert problem solver. ${ }^{22}$

\section{CONCLUSIONS AND IMPLICATIONS FOR FURTHER RESEARCH}

This paper outlined phenomenographic research that described students' various approaches to solving physics problems, through the analysis and interpretation of interview data with 22 introductory students. The hierarchical approaches to problem solving were represented by an outcome space which consisted of four main categories: scientific, plug-and-chug, and memory based approaches, and no clear approach. The plug-and-chug category was clearly split into two subcategories, structured and unstructured. This study confirms that the majority of students who begin higher-level 
education do not approach problem solving in a strategic or scientific manner. Most of these students used a plug-andchug approach by identifying variables and trying to find some formula, appropriate or not. However, the result of this research is an outcome space that allows for a better description of the problem solving approaches of a class of students. The researchers do not claim that these categories can be used to describe all students' problem solving approaches; however, as the cohort was mixed from a variety of academic backgrounds (within the Irish system) the outcome space seems to describe the problem solving state of first-year college physics students in Ireland. Also, these categories have similarities to those observed by another group of researchers within the United States higher-education system.

Ongoing research in this area involves investigating how the students' conceptual knowledge affects their ability and approach to problem solving. Another aspect of the study will involve examining students' approaches to problem solving as they progress through their undergraduate studies; perhaps as their conceptual framework becomes more coherent, their approach may become more scientific.

Also, during the course of the present study, the pedagogical delivery of the physics material was not taken into consideration, so further research will examine the development of both conceptual knowledge and problem solving skills within the different learning environments in which students learn physics. In addition, these studies will inherently inform the pedagogical processes that will support the development of problem solving skills and encourage students to more toward the highest category of scientist.

\section{ACKNOWLEDGMENTS}

We wish to thank all members of the Physics Education Research Group in Dublin Institute of Technology, and also give a special thank you to Matthew Moelter for his valuable suggestions while on sabbatical here from California Polytechnic State University. The authors would also like to thank the anonymous reviewers for their constructive suggestions and recommendations. L.W. acknowledges DIT and Focas Institute support.

\section{APPENDIX: INDIVIDUAL INTERVIEW PROBLEMS}

(1) If I drop a $2 \mathrm{~kg}$ watermelon from the top of a threestory building, say around $10 \mathrm{~m}$ high, how fast will the watermelon be going when it hits the ground?

(2) Say you are standing here, holding out your hand, which is about $2 \mathrm{~m}$ above the ground, and you throw a ball straight up. If the ball leaves your hand with a speed of $15 \mathrm{~m} / \mathrm{s}$, how long will the ball be in the air before it hits the ground?

(3) Just for the fun of it, you and a friend decide to enter the famous Tour de France bicycle race. You are riding along at a comfortable speed of $10 \mathrm{~m} / \mathrm{s}$ when you see in your mirror that your friend is going to pass you at what you estimate to be a constant $15 \mathrm{~m} / \mathrm{s}$. You will, of course, take up the challenge and accelerate just as she passes you until you pass her. If you accelerate at a constant 0.25 meters per second each second until you pass her, how long will she be ahead of you?

(4) A car with a mass of $1300 \mathrm{~kg}$ is initially moving at a speed of $40 \mathrm{~m} / \mathrm{s}$ when the brakes are applied and the car is brought to a stop in $15 \mathrm{~m}$. Assuming that the force that stops the car is constant, find the magnitude of that force, and the time required for the change in speed.

(5) You have been hired to design the interior of a special executive express elevator for a new office building. This elevator has all the latest safety features and will stop with an acceleration of $g / 3$ in case of any emergency. The management would like a decorative lamp hanging from the unusually high ceiling of the elevator. You design a lamp that has three sections, which hang one directly below the other. Each section is attached to the previous one by a single thin wire, which also carries the electric current. The lamp is also attached to the ceiling by a single wire. Each section of the lamp weighs $7.0 \mathrm{~N}$. Because the idea is to make each section appear that it is floating on air without support, you want to use the thinnest wire possible. Unfortunately, the thinner the wire, the weaker it is. To determine the thinnest wire that can be used for each stage of the lamp, calculate the force on each wire in case of an emergency stop.

(6) Two blocks, one with a mass of $1 \mathrm{~kg}$ and the other with a mass of $2 \mathrm{~kg}$, start from rest. They each experience a constant force of $10 \mathrm{~N}$ for $1 \mathrm{~s}$. What are their kinetic energies after the force has been applied?
${ }^{1}$ B. Bowe, Assessing problem-based learning: A case study of a physics problem-based learning course. in A Handbook of Enquiry and Problem-Based Learning in Higher Education: Irish Case Studies and International Perspectives, edited by T. Barrett and I. Labhrainn (AISHE and CELT, NUI Galway, 2005)

${ }^{2}$ B. Bowe and J. Cowan, A comparative evaluation of problembased learning in physics: A lecture-based course and a problembased course. in Challenging Research into Problem-Based Learning, edited by M. Savin-Baden and K. Wilkie (SRHE/ Open University Press, Buckingham, 2004)

${ }^{3}$ R. Howard and B. Bowe, PBL in a first year physics laboratory, in Proceedings of a Pathway to Better Learning Conference, Can- cun, Mexico, 2004 (unpublished).

${ }^{4}$ E. Mazur, Peer instruction-A user's manual (Prentice-Hall, Englewood Cliffs, NJ, 1997).

${ }^{5}$ P. Heron and D. Meltzer, Guest Editorial, The future of physics education research: Intellectual challenges and practical concerns. Am. J. Phys. 73, 390 (2005).

${ }^{6}$ C. Hoellwarth, M. J. Moelter, and R. D. Knight, A direct comparison of conceptual learning and problem solving ability in traditional and studio style classrooms. Am. J. Phys. 73, 459 (2005).

${ }^{7}$ P. Heller, R. Keith, and S. Anderson, Teaching problem solving through cooperative grouping. Part 1: Group versus individual 
problem solving. Am. J. Phys. 60, 627 (1991).

${ }^{8} \mathrm{P}$. Heller and M. Hollabaugh, Teaching problem solving through cooperative grouping. Part 2: Designing problems and structuring groups. Am. J. Phys. 60, 637 (1991).

${ }^{9}$ B. Thacker, E. Kim, K. Trefz, and S. M. Lea., Comparing problem solving performance of physics students in inquiry-based and traditional introductory physics courses. Am. J. Phys. 62, 627 (1994).

${ }^{10}$ D. Maloney, Research on problem solving: Physics. in Handbook of Research on Science Teaching and Learning, edited by D. Gabel (MacMillan, New York, 1994).

${ }^{11}$ L. Hsu, E. Brewe, T. M. Foster, and K. A. Harper, Resource Letter RPS-1: Research in problem-solving. Am. J. Phys. 12, 1147 (2004).

${ }^{12} \mathrm{D}$. Meltzer, Relation between students" problem-solving performance and representational format. Am. J. Phys. 73, 463 (2005)

${ }^{13}$ W. J. Leonard, R. J. Dufresne, and J. P. Mestre, Using qualitative strategies to highlight the role of conceptual knowledge in solving problems. Am. J. Phys. 64, 1495 (1996).

${ }^{14}$ E. Mazur, Qualitative vs. quantitative thinking: Are we teaching the right thing? Opt. Photonics News 3, 38 (1992).

${ }^{15}$ E. Kim and S. J. Pak, Students do not overcome conceptual difficulties after solving 1000 traditional problems. Am. J. Phys. 70, 759 (2001).

${ }^{16}$ E. Redish, Changing student ways of knowing: What should our students learn in a physics class? In Proceedings of World View on Physics Education 2005: Focusing on Change, New Delhi, 2005 (World Scientific Publishing Co.), Singapore, (in press), http://www.physics.umd.edu/perg/papers/redish/IndiaPlen.pdf

${ }^{17}$ F. Reif and J. I. Heller, Knowledge structure and problem solving in physics. Educ. Psychol. 17, 102 (1982).

${ }^{18}$ A. Van Heuvelen, Learning to think like a physicist: A review of research-based instructional strategies. Am. J. Phys. 59, 891 (1991)

${ }^{19}$ J. H. Larkin, J. McDermott, D. P. Simon, and H. A. Simon, Expert and novice performance in solving physics problems. Science 208, 1335 (1980).

${ }^{20}$ A. G. Priest and R. O. Lindsay, New light on novice-expert differences in physics problem solving. J. Psychol. 83, 389 (1992).

${ }^{21} \mathrm{~F}$. Reif and S. Allen, Cognition for interpreting scientific concepts. Cogn. Instruct. 9, 1 (1992).

${ }^{22} \mathrm{~K}$. Schultz and J. Lockhead, A view from physics. in Toward a Unified Theory of Problem Solving: Views from the Content Domains, edited by M. U. Smith (Erlbaum, Hillsdale, NJ, 1991).

${ }^{23}$ M. S. Sabella, Using the context of physics problem solving to evaluate the coherence of student knowledge. Ph.D. dissertation, University of Maryland, http://www.physics.umd.edu/perg/ dissertations/Sbella/ (1999).

${ }^{24}$ M. S. Sabella and E. F. Redish, Knowledge activation and organisation in physics problem-solving. Am. J. Phys. 75, 1017 (2007).

${ }^{25} \mathrm{http}: / /$ www.physics.umd.edu/perg/

${ }^{26}$ E. F. Redish, R. N. Steinberg, and J. M. Saul, Student difficulties with math in physics: Giving meaning to symbols. Proceedings of the 113th AAPT National Meeting, College Park, MD, 1996 AAPT Announcer, 26, 70 (1996).

${ }^{27}$ J. Tuminaro and E. F. Redish, Understanding students' poor performance on mathematical problem solving in physics, in Proceedings of the Physics Education Research Conference, Madi- son, WI, 2003 AIP Conference Proceedings, edited by J. Marx, S. Franklin, and K. Cummings, (2004), vol. 720, pp. 113-116.

${ }^{28}$ J. Tuminaro and E. F. Redish, Students' use of mathematics in the context of physics problem solving: A cognitive model (unpublished).

${ }^{29}$ E. F. Redish, R. E. Scherr, and J. Tuminaro, Reverse engineering the solution of a "simple" physics problem: Why learning physics is harder than it looks. Phys. Teach. 44, 293 (2006).

${ }^{30} \mathrm{~J}$. Tuminaro, A cognitive framework for analyzing and describing introductory students' use and understanding of mathematics in physics. Ph.D. dissertation, University of Maryland, (2003) http://www.physics.umd.edu/perg/dissertations/Tuminaro/

${ }^{31}$ A. Collins and W. Ferguson, Epistemic forms and epistemic games: Structures and strategies to guide inquiry. Educ. Psychol. 28, 25 (1993).

${ }^{32}$ F. Marton, Phenomenography-describing conceptions of the world around us. Instr. Sci. 10, 177 (1981).

${ }^{33}$ F. Marton, Phenomenography—a research approach to investigating different understandings of reality. J. Thought 21, 28 (1986).

${ }^{34} \mathrm{~F}$. Marton, Phenomenography, in The International Encyclopedia of Education, 2nd edition, edited by T. Husen and T. N. Postelthwaite (Pergamon, Oxford, 1994), Vol. 8, pp. 4424-4429.

${ }^{35} \mathrm{~F}$. Marton and S. Booth, Learning and Awareness (Laurence Erlbaum Associates, Hillsdale, NJ, 1997)

${ }^{36}$ F. Marton and S. Saljo, Approaches to learning, in The Experience of Learning: Implications for Teaching and Studying in Higher Education, 2nd edition, edited by F. Marton, D. Hounsell, and N. J. Entwistle (Scottish Academic Press, Edinbugh, 1997).

${ }^{37}$ N. Entwistle, Introduction: Phenomenography in higher education. Higher Educ. Res. Dev. 16, 127 (1997).

${ }^{38}$ M. Prosser and K. Trigwell, Understanding Learning and Teaching. The Experience in Higher Education (Open University Press, Buckingham, U.K., 1999).

${ }^{39}$ M. Wihlborg, Student nurses' conceptions of internationalism in general and as an essential part of Swedish nurses' education. Higher Educ. Res. Dev. 23, 433 (2004).

${ }^{40}$ A. B. Arons, Phenomenology and logical reasoning in introductory physics courses. Am. J. Phys. 50, 13 (1982).

${ }^{41}$ B. Hasselgren and D. Beach, Phenomenography- "a good looking brother" of phenomenology? Higher Educ. Res. Dev. 16, 191 (1997)

${ }^{42} \mathrm{M}$. Uljens, On the philosophical foundation of phenomenography, in Reflections on Phenomenography - Toward a methodology?, edited by G. Dall' Alba and B. Hasselgren (Goteborg: Acta Universitatis Gothoburgensis, 1996), pp. 105-130 http:// www.ped.gu.se/biorn/phgraph/misc/constr/phlo.phgr.html

${ }^{43} \mathrm{~J}$. A. Bowden, The nature of phenomenographic research, in Phenomenography, edited by J. A. Bowden and E. Walsh (RMIT Publishing, Melbourne, 2000).

${ }^{44}$ G. Dall'Alba, E. Walsh, J. Bowden, E. Martin, G. Masters, P. Ramsden, and A. Stephanou, Textbook treatments and students' understanding of acceleration. J. Res. Sci. Teach. 30, 621 (1993).

${ }^{45}$ E. Walsh, G. Dall"Alba, J. Bowden, E. Martin, F. Marton, G. Masters, P. Ramsden, and A. Stephanou, Physics students' understanding of relative speed: A phenomenographic study. J. Res. Sci. Teach. 30, 1133 (1993).

${ }^{46}$ J. Bowden, G. Dall"Alba, E. Martin, D. Laurillard, F. Marton, G. Masters, P. Ramsden, A. Stephanou, and E. Walsh, Displacement, velocity and frames of reference: Phenomenographic studies of students' understanding and some implications for teach- 
ing and assessment. Am. J. Phys. 60, 262 (1992).

${ }^{47}$ M. Sharma, R. Millar, A. Smith, and I. Sefton, Students' understanding of gravity in an orbiting space-ship. Res. Sci. Educ. 34, 267 (2004).

${ }^{48} \mathrm{http} / / /$ groups.physics.umn.edu/physed/research/cpr/crintro.html

${ }^{49}$ M. T. H. Chi, Thinking aloud, in The Think Aloud Method, edited by M. V. van Someren, Y. F. Barnard, and J. A. C. Sandberg, (Academic Press, London, 1994).

${ }^{50} \mathrm{An}$ honors degree is a level 8 programe and an ordinary degree is a level 7 programe as defined by the National Qualifications Authority of Ireland (NQAI), http://www.nqai.ie/en/ PoliciesandProcedures/
${ }^{51}$ Department of Education and Science, http://www.education.ie/ home/home.jsp?pcategory $=17216 \&$ ecategory

$=173131$ \&anguage $=\mathrm{EN}$

${ }^{52}$ R. K. Thornton and D. R. Sokoloff, Assessing student learning of Newton's laws: The force and motion conceptual evaluation and the evaluation of active learning laboratory and lecture curricula. Am. J. Phys. 66, 338 (1998).

${ }^{53}$ H. D. Young, R. A. Freedman, T. R. Sandin, and A. Lewis Ford, Sears and Zemansky's University Physics, 10th edition (Addison Wesley, New York, 1999). 